\title{
Energy and Exergy Analysis of a Simple Gas Turbine Cycle with Wet Compression
}

\author{
E. H. Betelmal ${ }^{1} \&$ S. A. Farhat ${ }^{1}$ \\ ${ }^{1}$ Department of Mechanical Engineering, Tripoli University, Faculty of engineering, Tripoli, Libya \\ Correspondence: E. H. Betelmal, Department of Mechanical Engineering, Tripoli University, Faculty of engineering, \\ Tripoli, Libya. E-mail: e.betelmal@hotmail.com
}

Received: February 28, 2018

Accepted: March 24, 2018

Online Published: April 4, 2018

doi:10.5539/mer.v8n1p30

URL: https://doi.org/10.5539/mer.v8n1p30

\begin{abstract}
A thermodynamic model of the wet compressor in a simple gas turbine cycle was investigated in this paper. A suitable quantity of water was injected into the compressor-stages where it evaporated. Subsequently, the steam and air were heated in the combustion chamber and expanded in the turbine. The wet compressor (WC) has become a reliable way to reduce gas emissions and increase gas turbine efficiency. In this study, the operational data of the simple gas turbine and the maximum amount of water that can be injected into the compressor were assessed, as well as a comparison between the dry compression, the wet compression and the isentropic compression. The performance variation due to water spray in the compressor and the effect of varying ambient temperature on the performance of gas turbine (thermal efficiency, power) was investigated, and the results are compared to the results of the same cycle with a dry compressor. The analytical formula of exergy destruction and results show that exergy destruction increases with water injection. The programming of the performance model for the gas turbine was developed utilizing the software IPSEpro. The results of the gas turbine with a wet compressor demonstrates a $12 \%$ reduction in the compressor exit temperature up to isentropic temperature. The compressor work decreased by $11 \%$ when using a wet compressor, this lead to an improvement in power output and efficiency However, the wet compressor increases the specific fuel consumption and heat rate of the gas turbine. There are limitations in the amount of steam that can be injected, $0.4 \mathrm{~kg} / \mathrm{s}$ of water was the optimum amount injected into the compressor.
\end{abstract}

Keywords: gas turbine, exergy analysis, exergy destruction, IPSEpro., wet compressor

\section{Introduction}

The world's wealthiest countries assumed obligated commitments to reduce greenhouse gas emissions under the Kyoto Protocol. The agreement requires these countries to consider ways to minimize adverse effects on developing countries of these actions, transmitted through trade (Babiker, Reilly, \& Jacoby, 2000). In recent years, various methods have been tested for improving the gas turbines performance. A thermodynamic model of wet compression in the simple gas turbine cycle is established in this paper. The performance of gas turbine cycles can be improved by injecting a suitable quantity of water into the compressor (Agrawal, Maharana, \& Badarinarayan, 2012). The real beneficial energy loss cannot be determined by the first law of thermodynamics because the real plant inefficiencies are not related to energy loss but to exergy destruction. Exergy analysis and the exergy destruction of each component of the gas turbine have been investigated as it can be used as a common measure of research quality along with quantity. Exergy decreases in this component due to the increase in entropy related to the evaporation of water. The benefits of water injection mostly rely on the increased heat capacity of the air-vapor mixture and the reduced power required by the compressor (Carrero, De Paepe, Bram, \& Contino, 2017). The combustion properties of different gaseous hydrocarbon mixtures at wet conditions did not vary significantly from each other except for the laminar burning velocity (Agrawal, Maharana, \& Badarinarayan, 2012). Wet Compression is perfectly suited for upgrading the peak load machine. A power increase can help take full advantage of high peak load electricity prices and therefore offers attractive financial payback options (Energy, n.d.). Wet Compression is designed to increase the power output of the gas turbine by reducing the work and an increasing mass flow throughout the turbine. These benefits can lead to the ability to produce more power in peaking and baseload operation. Wet compressor injection flow rates are typically expressed as a percentage of air intake usually from 0.5 to 2 percent. Rarely, this number can go higher. 


\section{System Analysis}

Wet compression is a process in which water droplets are injected between the stages of the compressor. As the water droplets evaporate in the stages of the compressor, it reduces the air temperature and therefore reduces the amount of work that must be done by the compressor. For a gas turbine cycle, the economic gain from water injection exists for the entire range of power efficiency (Energy, n.d.). The net effect is a reduction in compressor work since one-half to two-thirds of the turbine output is typically used to drive the compressor, a reduction in the compressor work directly translates to an increase in the net turbine output. Wet compression also results in a significant reduction in the compressor discharge temperature which requires higher fuel flow rates to achieve base load firing temperatures. The additional mass flow of water and incremental fuel flow also contribute to the increase in the power from the gas turbine. The major benefits of wet compression are an increase in turbine performance, an improvement in the heat rate and in many instances, a reduction in $\mathrm{NO}_{\mathrm{x}}$ levels (Energy, n.d.).

The system as shown in Figure 1 is constructed from the schematic diagram of the gas cycle system with a wet compressor. First, in the wet compression system, air is cooled by introducing water into the air in the form of fine water droplets (spray form). The reduction in the air temperature is limited by the ability of air to absorb water. The purpose of the compressor is to compress the inlet air (raise its pressure). After the air-water mixture is discharged from the compressor, it is sent to the combustor where it is mixed with fuel and combustion takes place. Fuel is mixed with the high-pressure air and burnt in special chambers called combustors. The hot pressurized gas exits the combustors at a very high temperature (up to $1100^{\circ} \mathrm{C}$ ). This gas then passes through a gas turbine, giving the turbine energy to spin the compressor and the power for a generator to produce electricity. Because some of its heat and pressure energy has been transferred to the turbine, the gas leaves the power turbine at a lower temperature and pressure. The IPSEpro program has been used to model and examine the thermodynamic cycles to determine the optimum mode of operation and configuration (Simulation Technology, 2016). This work examines the performance of a gas turbine cycle, according to the second law of thermodynamics using the exergy analysis in the operation of the cycle.
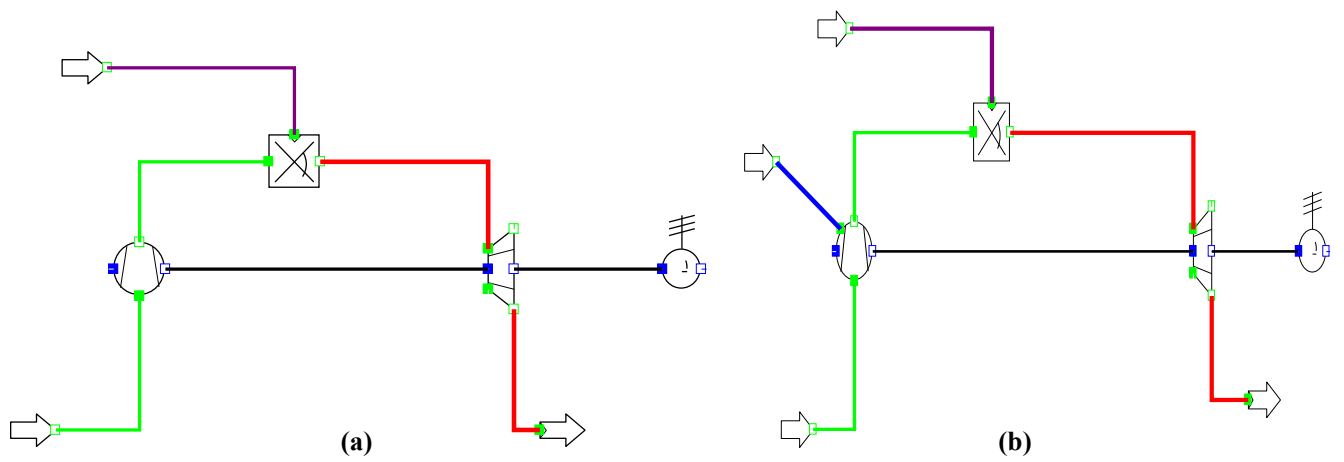

Figure 1. Brayton and inverse Brayton cycles with steam injection

\section{Thermodynamic Analysis}

The present study introduces a comparative energy and exergy analysis for the wet compressor of the gas cycles. The analysis investigated the cycle performance due to changes in the ambient temperatures.

\subsection{Assumptions}

The following assumptions are made to simplify the calculations however they can be refined to reach more real solutions. The main assumptions are:

Methane $\left(\mathrm{CH}_{4}\right)$ gas enters a steady-flow adiabatic combustion chamber at $25^{\circ} \mathrm{C}$ and $25 \mathrm{bar}$.

Mass of air $m_{\text {air }}=30 \mathrm{~kg} / \mathrm{s}$

Design Parameters

Ambient temperature $\mathrm{T}_{\mathrm{a}}$

Inlet pressure $\mathrm{P}_{\text {air }}$ 
The input data for compressor

Compressor isentropic efficiency $\eta_{\mathrm{s}} \quad 0.87$

Compressor mechanical efficiency $\eta_{\mathrm{m}} \quad 0.98$

Pressure ratio $\mathrm{P}_{2} / \mathrm{P}_{1}$

Pressure drop in the combustion chamber $(\Delta \mathrm{P}) \quad 0.1$ bar

The input data for turbine:

Turbine mechanical efficiency $\eta_{\mathrm{m}} \quad 0.99$

Turbine isentropic efficiency $\eta_{\mathrm{s}} \quad 0.9$

Turbine inlet exhaust gas temperature $\mathrm{T}_{\max } \quad 1100^{\circ} \mathrm{C}$

The characteristics of heat exchanger are:

Pressure drop of the hot temperature side $\quad 0.1 \mathrm{bar}$

Pressure drop of the low temperature side $\quad 0.1 \mathrm{bar}$

The temperature increase of the air during the compression is:

$$
\left(\frac{d T_{1-2}}{T_{1}}\right)_{\text {actual }}=\left(\left(\frac{P_{2}}{P_{1}}\right)^{\frac{\gamma-1}{\gamma}}-1\right) / \eta_{s}
$$

$\mathrm{T}_{1}$ : Compressor inlet Temperature $[\mathrm{K}]$

$\mathrm{T}_{2}$ : Compressor outlet Temperature $[\mathrm{K}]$

$\mathrm{dT}_{1-2}$ : Temperature different between 1 and 2

$\mathrm{P}_{1}$ : Compressor inlet pressure

$\mathrm{P}_{2}$ : Compressor outlet pressure

The pressure ratio $P_{3} / P_{2}$ can be obtained directly from the combustion chamber pressure loss

$$
\frac{P_{3}}{P_{2}}=1-\left[\Delta P / P_{2}\right]
$$

The overall efficiency of the combined cycle $\left(\eta_{C C}\right)$ is calculated using the following equation.

$$
\eta=\frac{P_{G}}{m_{f} * \text { Heating vaue }}
$$

Where:

$P_{G} \quad$ is the power of the gas turbine

\section{Exergy Destruction in the Components of Combined Cycle}

The complex thermodynamic analysis of combined cycle has been based on the second law of thermodynamics because the conventional first law analysis of any thermodynamic system has the capability to determine the energy distribution across the system boundaries but does not explain the means of energy degradation that cause decreases in the power output of the system. The exergy analyses for the gas turbine components have been conducted to determine the energy loss caused by irreversible processes. Exergy analysis usually predicts the thermodynamic performance of an energy system and the efficiency of the system components by quantifying the entropy generation of the components. This analysis provides a tool for the optimal design and operation of complex thermal systems. The exergy and irreversibility equations for each component are written as follows [7],

Compressor: The exergy and irreversibility in compressor is given by

$$
\begin{gathered}
\Delta \varphi=\left(\left(\left(m_{a} * h_{1}\right)+\left(m_{w} * h_{w}\right)\right)-\left(\left(m_{w}+m_{a}\right) * h_{2}\right)\right)-298 *\left(\left(\left(m_{a} * s_{1}\right)+\left(m_{w} * s_{w}\right)\right)-\left(\left(m_{w}+m_{a}\right) * s_{2}\right)\right) \\
I=T_{0} *\left[\left(\left(m_{a}+m_{w}\right) * s_{2}\right)-\left[\left(m_{a} * s_{a}\right)+\left(m_{w} * s_{w}\right)\right]\right]
\end{gathered}
$$


Combustion Chamber: As an approximation, the virtual power is used to calculate the exergy of the combustor component. The exergy balance of this component and exergy loss due to irreversibility in the combustion chamber is given by:

Where

$$
\begin{gathered}
\varphi_{c . c}=Q_{i n}+T_{o} S_{g e n} \\
I_{c \cdot c}=T_{0} S_{g e n}
\end{gathered}
$$

$$
S_{g e n}=\left(\dot{m}_{a}+\dot{m}_{f}\right)\left(c_{p} \ln \frac{T_{3}}{T_{2}}\right)-\frac{\dot{Q}_{i n}}{T_{a v}}
$$

4.1 Turbine

$$
\text { And } T_{a v}=\text { average }\left(\mathrm{T}_{3}, \mathrm{~T}_{2}\right)
$$

The exergy loss due to irreversibility in gas turbine is given by:

Where

$$
\begin{gathered}
\varphi_{T}=m_{g}\left(h_{3}-h_{4}\right)-T_{o} m_{g}\left(s_{3}-s_{4}\right) \\
I_{G T}=m_{g} T_{o}\left(s_{4}-s_{3}\right)
\end{gathered}
$$

$$
\left(s_{4}-s_{3}\right)=C_{P g} \ln \frac{T_{4}}{T_{3}}-R_{g} \ln \frac{P_{4}}{P_{3}}
$$

And

$$
R_{g}=C_{P g} \frac{(\gamma-1)}{\gamma}
$$

\section{Discussion of the Results}

Based upon the methodology developed and the thermodynamic equations shown, the effect of ambient condition on the performance and on the destruction of exergy due to irreversibility in various components of the gas turbine, with and without water injection into the compressor is displayed graphically. The following figures show the change the performance of the gas turbine with changing ambient temperature and compression ratio. Exergy destruction is obtained from the exergy analysis.

Figure 2 shows the compressor discharge temperature increasing because of increasing ambient temperature. The minimum compressor discharge temperature may reach an isentropic temperature, which can be obtained by using a wet compressor $(0.4 \mathrm{~kg})$, the result shows the compressor exit temperature is reduced by $12 \%$ from the compressor without water injection.

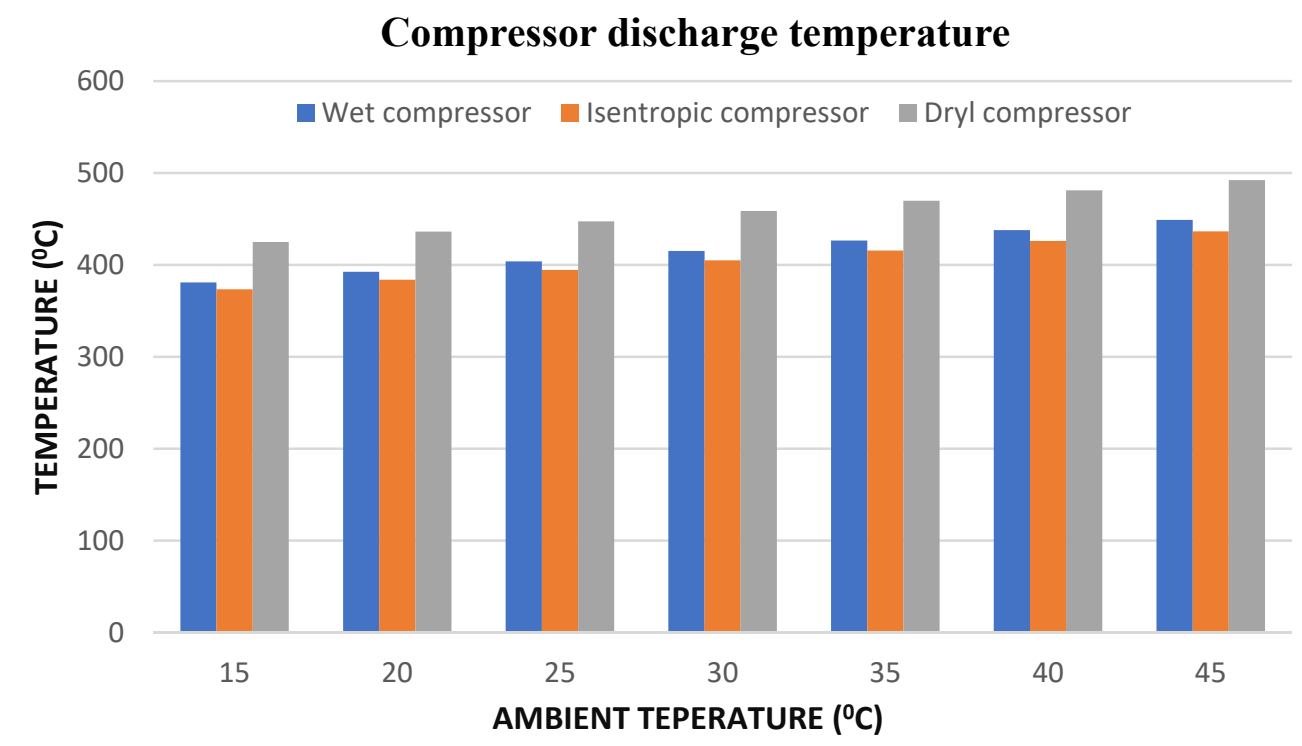

Figure 2. The compressor discharge temperature as a function of ambient temperature in three cases 
The variation of the compressor exit temperature with the water mass injected at a different compression ratio is shown in figure 3.

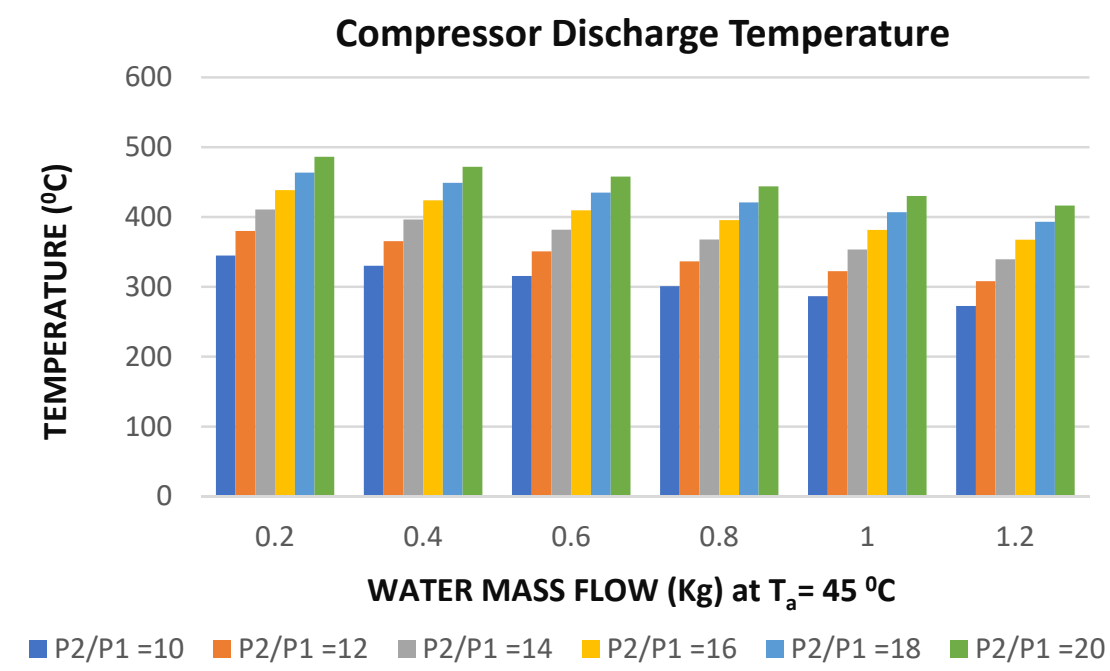

Figure 3. The compressor exit temperature as a function of water mass flow and a pressure ratio

The following figure shows an increase in the compressor work as the ambient temperature is increased. These figures show a significant decrease in the compressor with the use of water injection and this leading to improvement in cycle power output.

\section{Compressor Work}

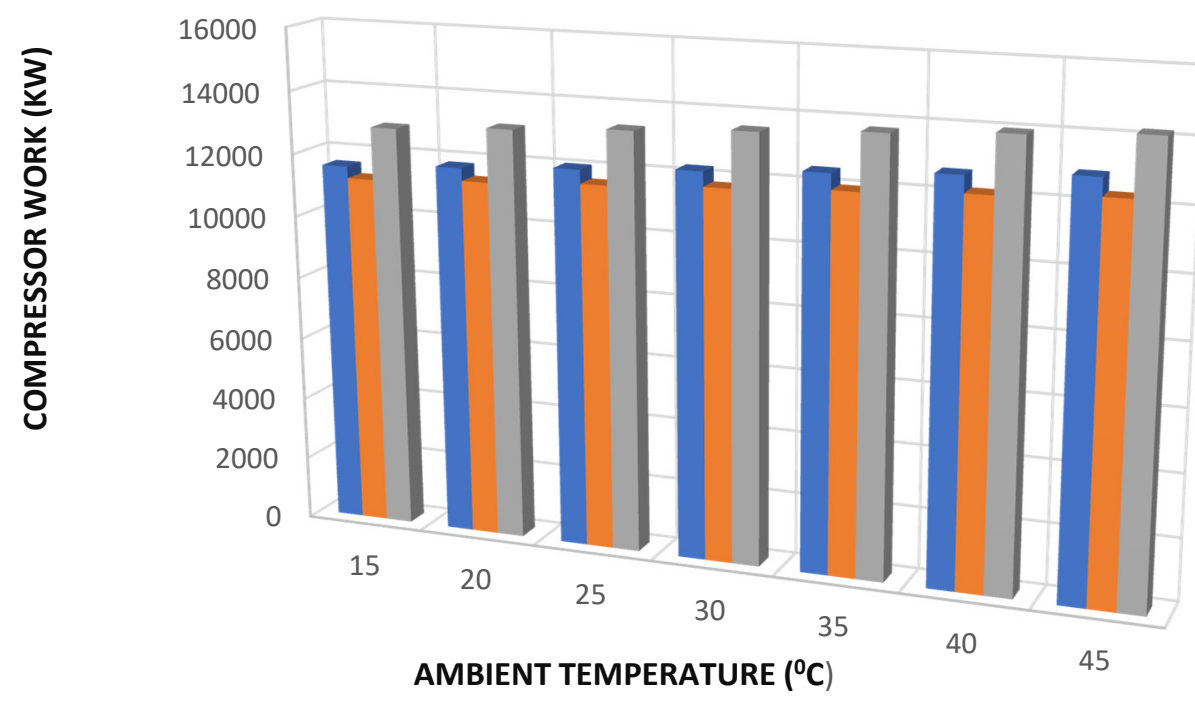

Wet compressor work $\mathrm{mw}=0.4$

- Isentropic Work

Dry Work

Figure 4. Compressor work as a function of ambient temperature in three cases 
It can be seen in figure 5 the effect of ambient temperature on the cycle efficiency in both cases (with and without water injection). With an increase in ambient temperature from $15{ }^{\circ} \mathrm{C}$ to $45^{\circ} \mathrm{C}$, the cycle efficiency reduces as the ambient temperature increases and improvement by $8 \%$ when the water injection into the compressor is used. The effect of the amount of water mass on the efficiency shown in figure 6.

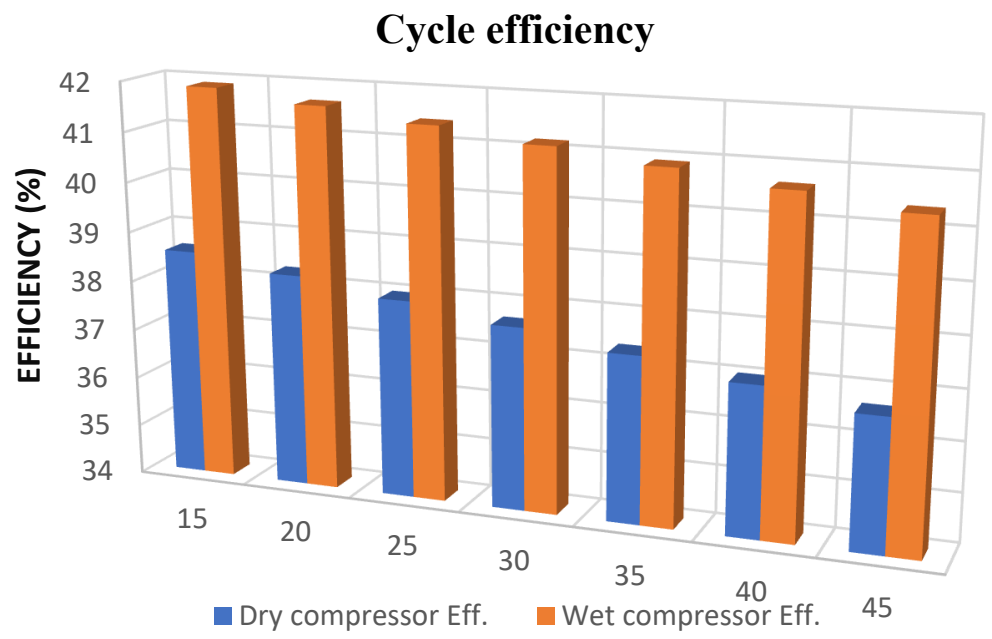

AMBIENT TEMPERATUR $\left({ }^{\circ} \mathrm{C}\right)$

Figure 5. The efficiency of the gas turbine cycle with and without injection as a function of ambient temperature

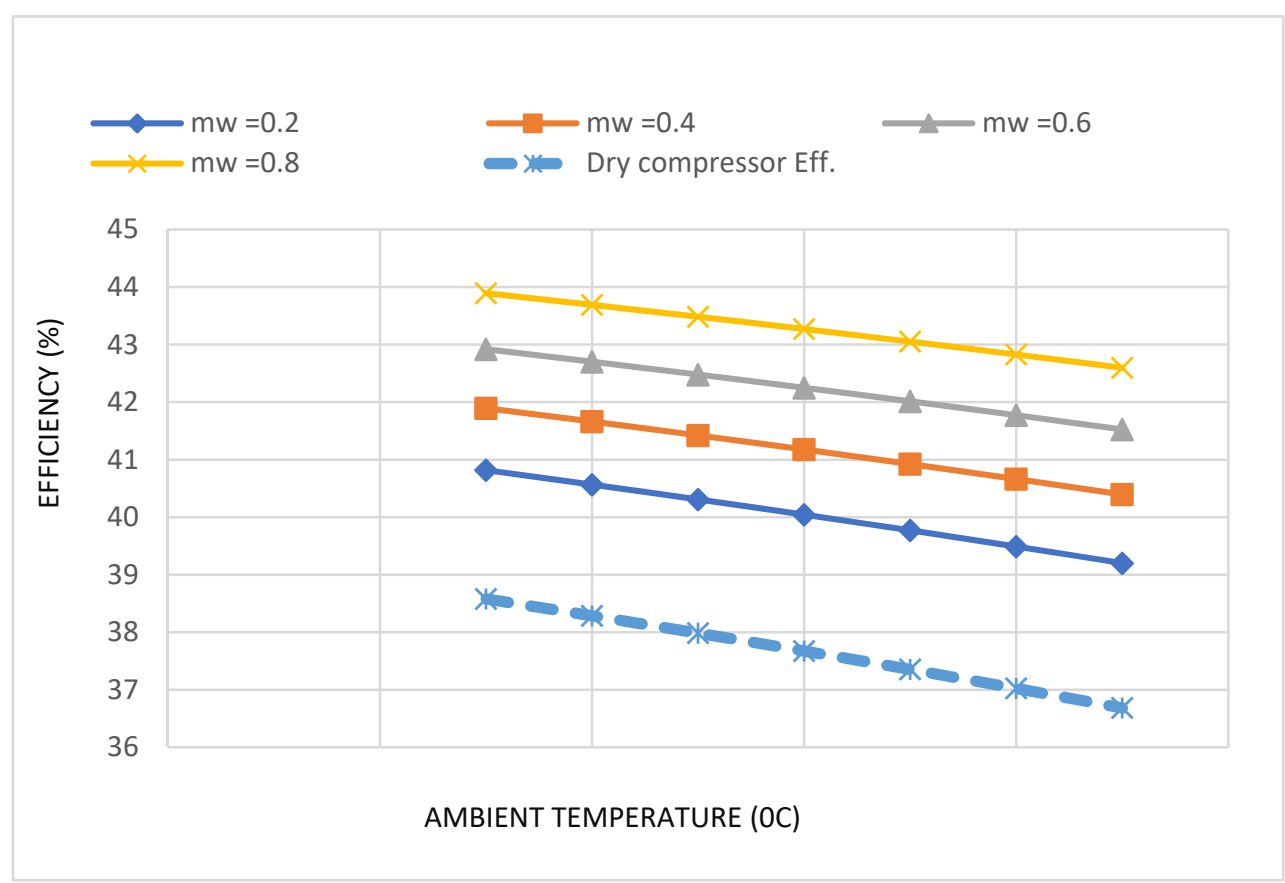

Figure 6. The efficiency of the gas turbine cycle with and without injection as a function of ambient temperature and water mass flow

Wet compression also results in a significant reduction in the compressor discharge temperature which requires higher fuel flow rates to achieve base load firing temperatures. Figure 7 demonstrates more fuel consumption with more water injection. 


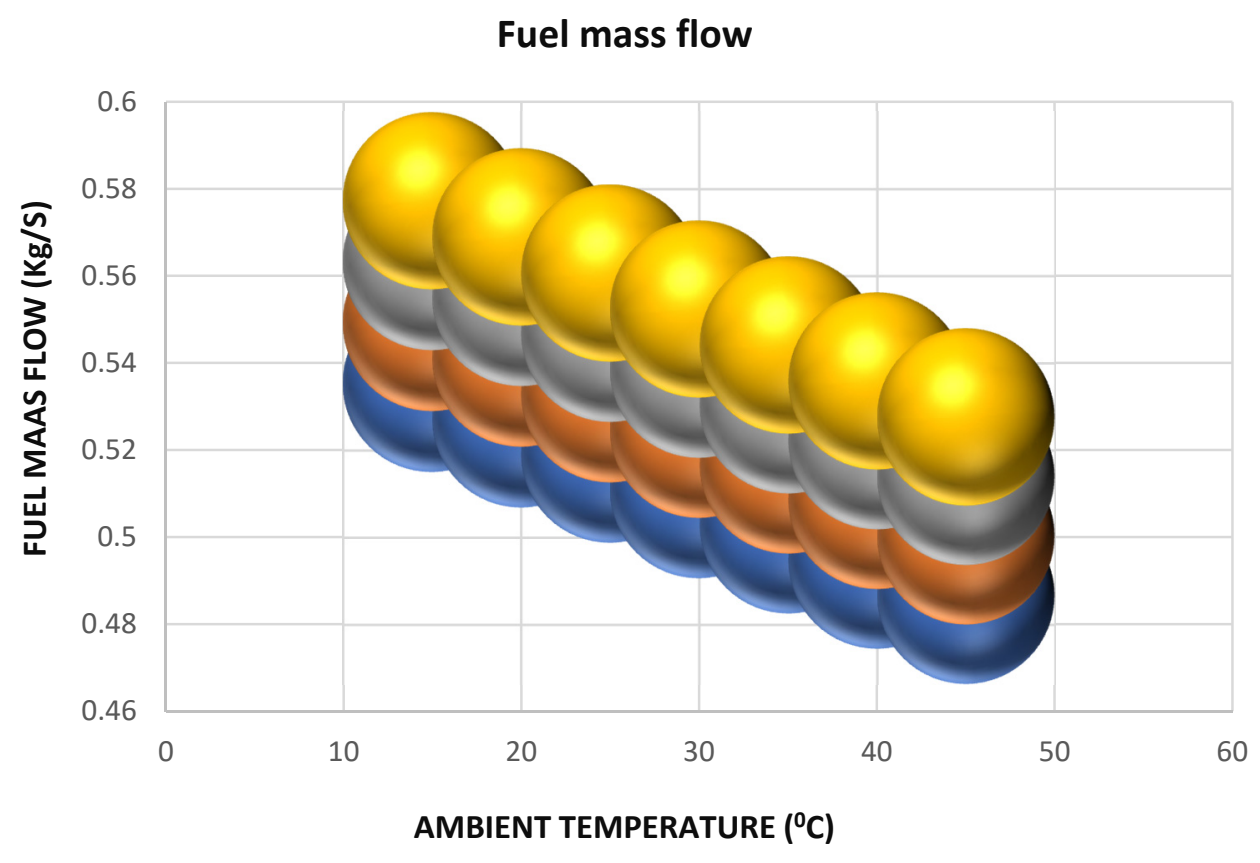

- $m w=0.2 \quad$ O $m w=0.4 \quad$ O $m w=0.6 \quad$ o $m w=0.8$

Figure 7. The fuel consumption as a function of ambient temperature and water mass flow

Figures 8 shows the improvement in the power output is up to $14 \%$ in the gas turbine

\section{Power output}

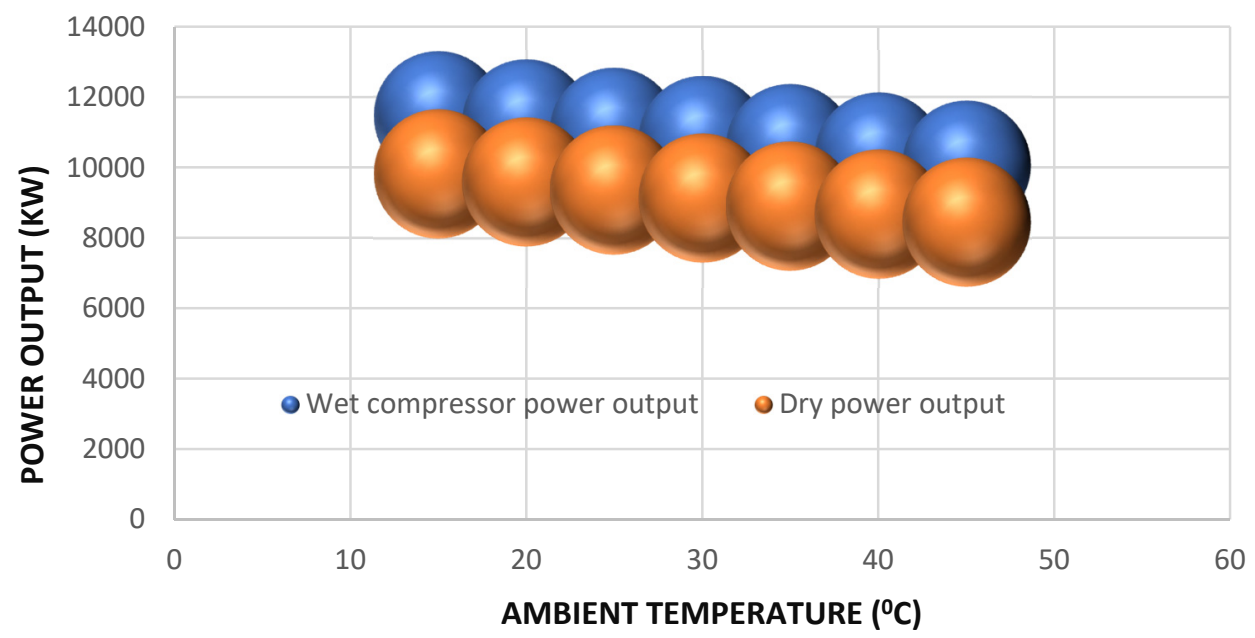

Figure 8. Power output with ambient temperature (with and without injection)

The variation of the power output with ambient temperature and compression ratio is shown in figure 9. At a high-pressure ratio of 20 , the power output is lower and as the pressure ratio decreases, the power increases. There is a similar behavior in the power output that can be seen in figure 10, as the water mass used for injection increases, the power generation increases. 


\section{Cycle Power Output}

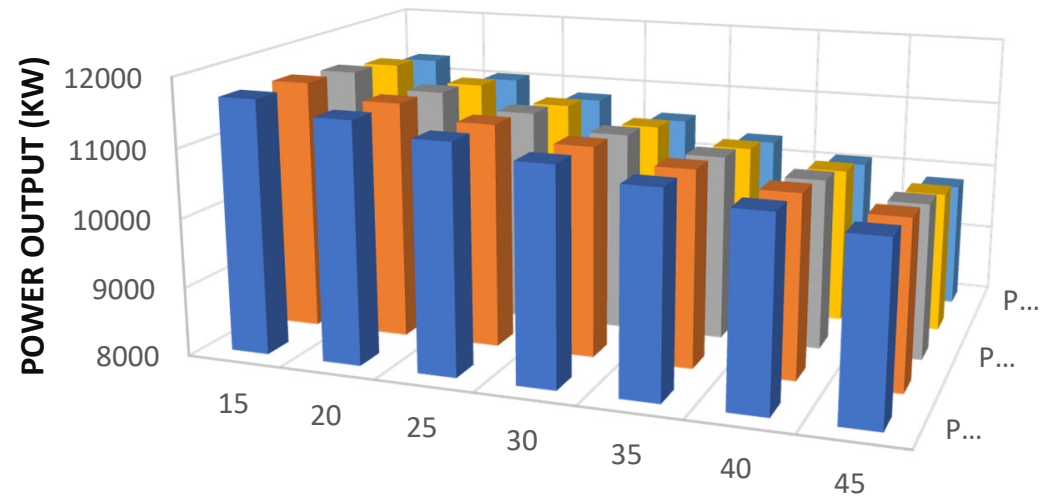

AMBIENT TEMPERATURE $\left({ }^{\circ} \mathrm{C}\right)$

口 $\mathrm{P} 2 / \mathrm{P} 1=12 \square \mathrm{P} 2 / \mathrm{P} 1=14 \square \mathrm{P} 2 / \mathrm{P} 1=16 \square \mathrm{P} 2 / \mathrm{P} 1=18 \quad \mathrm{P} 2 / \mathrm{P} 1=20$

Figure 9. The power output of the cycle with ambient temperature at different pressure ratio

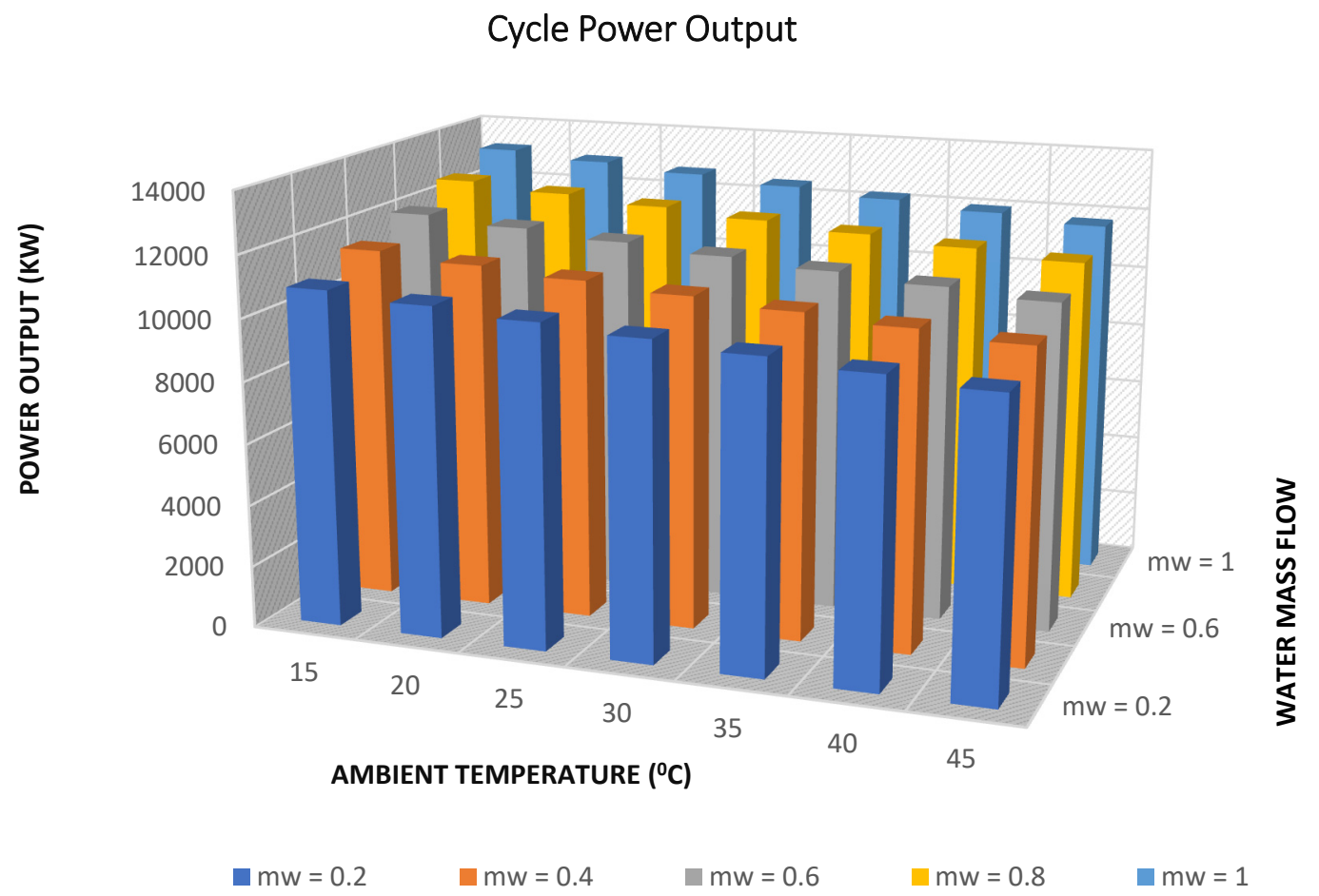

Figure 10. The power output of the cycle with ambient temperature at different water mass flow 


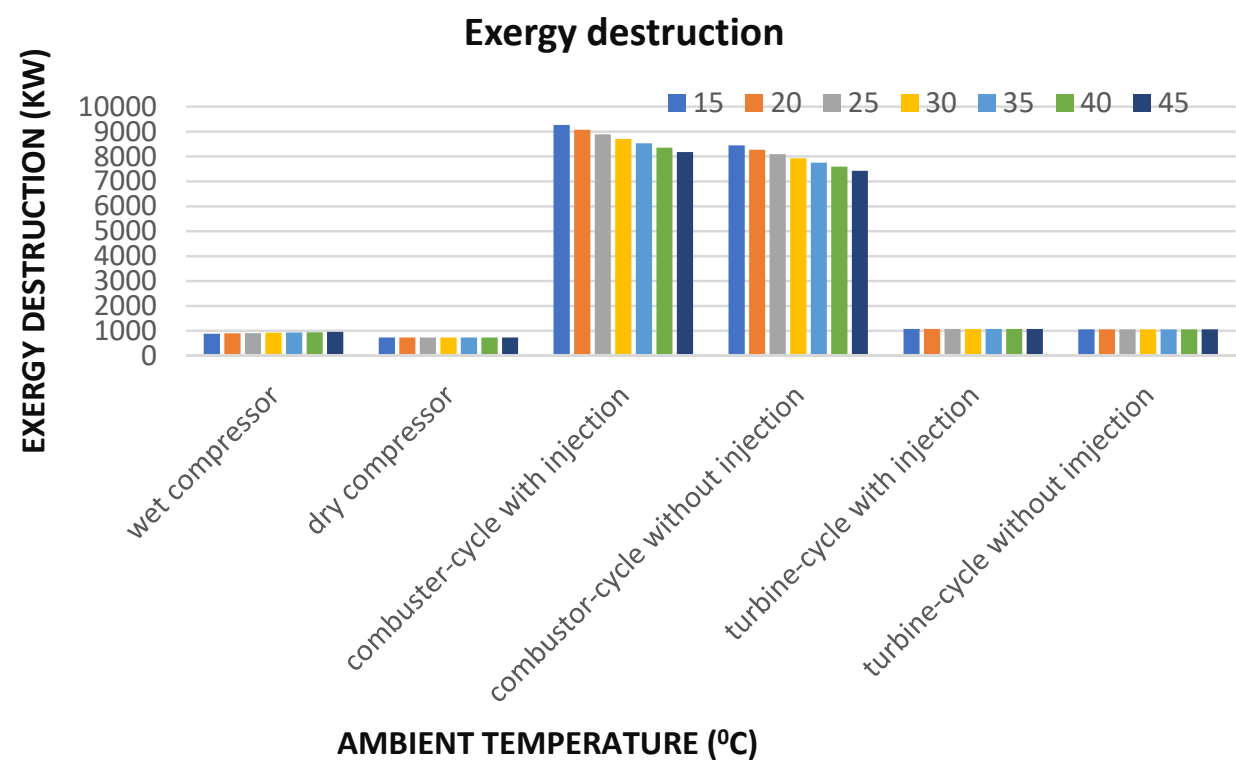

Figure 11. Exergy destruction of the gas turbine components with ambient temperature

The exergy of the compressor is affected by the quantity of water that is injected into the compressor. Figure 12 shows the exergy loss in the compressor with variation in the water mass flow and ambient temperature. There is a clear effect of the water mass flow on the exergy loss in the compressor. When a high amount of water is injected $(1 \mathrm{~kg} / \mathrm{s})$, the exergy loss in the compressor will be higher and as the water mass injection reduces to $0.2 \mathrm{~kg} / \mathrm{s}$ the exergy loss will be minimized.

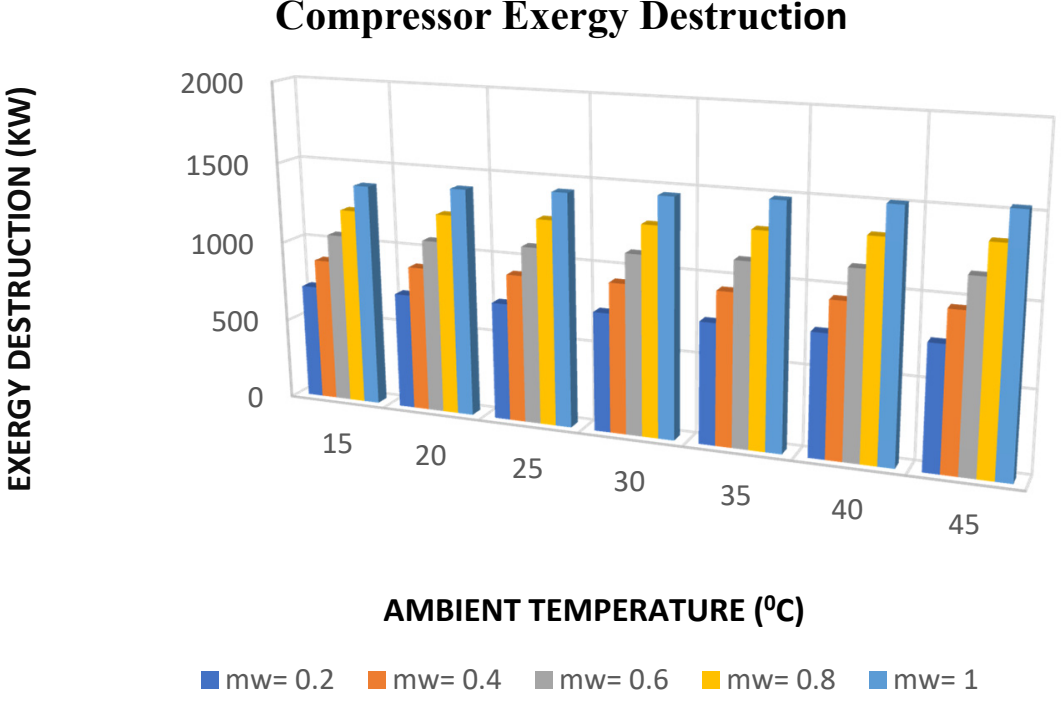

Figure 12. Exergy destruction of the compressor with ambient temperature at different water mass flow

Figures 13 shows the exergy loss in the compressor with variation in the compressor pressure ratio and ambient temperature. There is a clear effect of the compressor pressure ratio of exergy loss in the compressor. Exergy destruction in the compressor is larger for a higher-pressure ratio (20) and higher amounts of water injection and as the compression ratio decreases (10), the exergy loss is minimized. At any condition as the compressor pressure ratio increases, the exergy loss increases 


\section{Compressor Exergy Destruction}

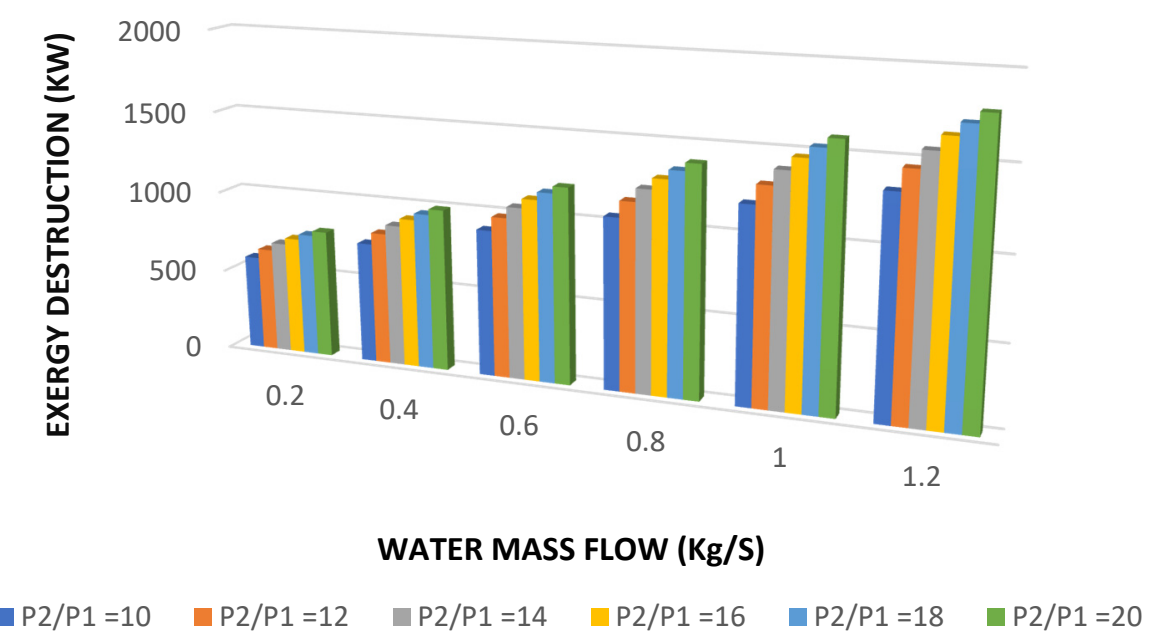

Figure 13. Exergy destruction of the compressor with ambient temperature at different pressure ratio

On the other hand, to get optimum performance while not increasing the exergy destruction significantly, the water mass injected must be the right amount.

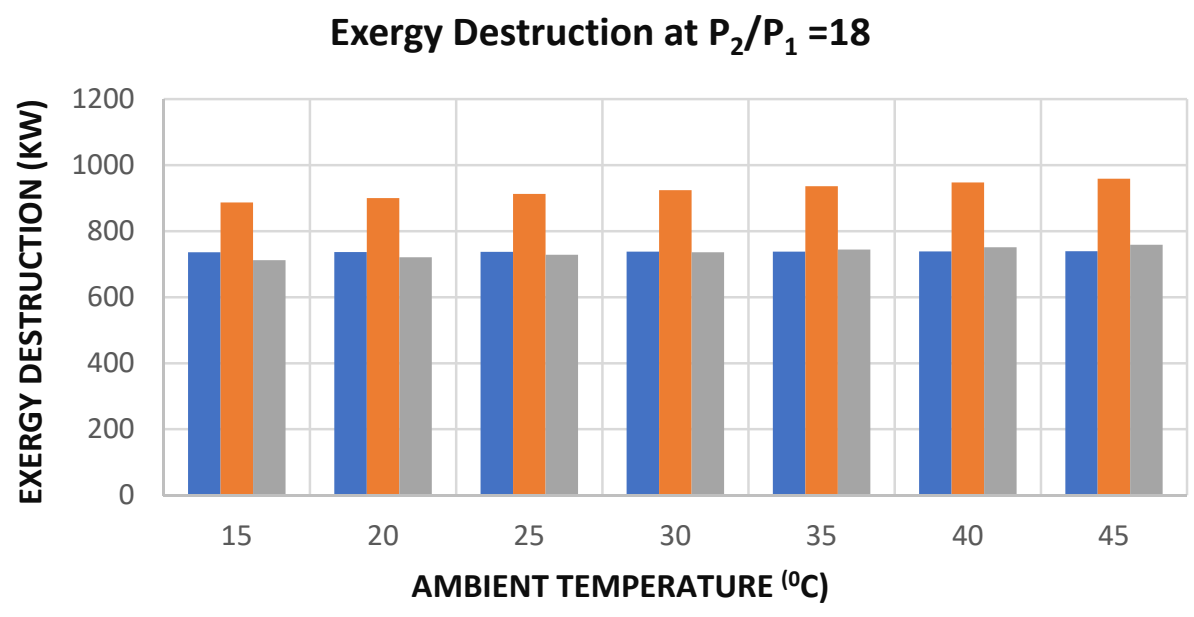

$\square$ dry compressor $\quad \mathrm{mw}=0.4 \quad \square \mathrm{mw}=0.2$

Figure 14. Exergy destruction of the compressor with ambient temperature

\section{Conclusion}

The simulation program IPSEpro has been applied successfully to the gas turbine cycle using conventional thermodynamic analysis involving an application of the first law of thermodynamics, also known as energy analysis. Exergy analysis is a thermodynamic analysis technique based on the second law of thermodynamics. The production of electricity and efficiency are highest at cooler times of the day and lowest at the hottest time of the day when they are needed most. Wet compression is a process in which water droplets are injected in between the stages of the compressorof a gas turbine, increasing the flow rate through the turbine. This causes an increase in the power output of a gas turbine and an increase in the electrical efficiency, thus that the power output of the gas turbine with steam injection will be higher than the common gas turbine. A wet compressor of the gas turbine can reach an electrical efficiency of up to 42 , this improvement in the efficiency has been accomplished without regeneration. Based on the 
above analysis, there are limitations on the amount of water that can be injected into the compressor, the following conclusions are made at different ambient conditions (pressure ratio and ambient temperature),

- Water cools the compressor and the cycle performance is dramatically improved.

- The exergy analysis gives a real picture on the losses which occur in the different plant components.

- More exergy losses occur in the compressor due to irreversibility and this must be reduced with advanced modern technology.

- There are clear effects in exergy losses with the changing in the pressure ratio. At higher pressure ratio, the exergy losses in the compressor are higher.

- The optimum turbine inlet temperature and pressure ratio should be the next focus of study for minimizing the total exergy losses in all the components.

\section{Reference}

Agrawal, S., Maharana, S. K., \& Badarinarayan, K. S. (2012). Thermodynamic Performance Analysis of a Combined Cycle System with Wet Compression. EST-M, 1(2).

Babiker, M., Reilly, J. M., \& Jacoby, H. D. (2000). The Kyoto Protocol and developing countries. Energy Policy, 28(8), 525-536. https://doi.org/10.1016/S0301-4215(00)00033-1

Cadavid, Y., Amell, A., Alzate, J., Bermejo, G., \& Ebratt, G. A. (2018). Analysis of Water-Fuel Ratio Variation in a Gas Turbine With a Wet-Compressor System by Change in Fuel Composition. Journal of Engineering for Gas Turbines and Power, 140(5), 052602. https://doi.org/10.1115/1.4038137

Carrero, M. M., De Paepe, W., Bram, S., \& Contino, F. (2017). Thermodynamic analysis of water injection in a micro gas turbine: Sankey and Grassmann diagrams. Energy Procedia, 105, 1414-1419. https://doi.org/10.1016/j.egypro.2017.03.527

Energy. (n.d.). In Siemens, Ingenuity for life. Retrieved from www.siemens.com/Energy

Jolly, S. (2002). Wet Compression-A Powerful Means of Enhancing Combustion Turbine Capacity. Power-Gen International, 1-12.

Kler, A. M., Zakharov, Y. B., \& Potanina, Y. M. (2017). Estimate for interstage water injection in air compressor incorporated into gas-turbine cycles and combined power plants cycles. Thermophysics and Aeromechanics, 24(3), 483-491.

Simulation Technology. (2016). IPSEpro Process Simulator (Manual Version 7).

Sonntag, R. E., \& Van Wylen, G. J. (1971). Introduction to thermodynamics: classical and statistical (No. 621.01 S6).

\section{Copyrights}

Copyright for this article is retained by the author(s), with first publication rights granted to the journal.

This is an open-access article distributed under the terms and conditions of the Creative Commons Attribution license (http://creativecommons.org/licenses/by/4.0/). 